\title{
Sustainable development and Brazilian states: comparison using the sustainability barometer
}

\author{
T. B. Cetrulo ${ }^{1} \&$ N. M. Cetrulo ${ }^{2}$ \\ ${ }^{I}$ Federal Institute of Education, \\ Science and Technology of Amazonas, Brazil \\ ${ }^{2}$ Federal University of Amazonas, Brazil
}

\begin{abstract}
The present study proposes to conduct a performance comparison of the 26 Brazilian states in relation to sustainable development using the State Sustainability Barometer (SSB) methodology. The Sustainability Barometer (SB) consists of a combination and graphical representation of a large number of indicators in two dimensions, namely, ecological well-being (EWB) and human well-being (HWB). This method aims to analyse the interaction patterns between people and the environment. In this sense, the 28 selected indicators are substantiated in the expansion of human freedom and the ability to support the ecosystem. Social indicators are represented by sub-dimensions related to demographics, education, economics, social justice, health, and safety, whereas ecological indicators are represented by sub-dimensions concerning health, environmental health, vegetation cover, soil pollution, and institutions. All of the indicators are published periodically by the Brazilian government in official documents. Results demonstrate that the Brazilian state with the best performance in sustainable development is Rio Grande do Sul (71.50 HWB; 67.43 EWB), followed by Santa Catarina (71.83 HWB; 66.42 EWB), and Paraná (66.26 HWB; 61.44 EWB). The state with the worst performance is Alagoas (30.34 HWB; 36.52 EWB), followed by Maranhão (35.93 HWB; 47.79 EWB), and Rondônia (50.46 HWB; 36.1 EWB). Hence, Southern Region states have a good performance in sustainable development, leveraged mainly by the quality of life indicators related to the population. Northeast Region states show a poor performance in the HWB and EWB indicators.
\end{abstract}

Keywords: sustainable development, indicators, sustainability barometer. 


\section{Introduction}

Several societies have begun to consider the sole intention of economic growth as outdated and are seeking sustainable development, whereby environmental and social factors are also considered to be of paramount importance. In this regard, various organisational structures of society are seeking ways to evaluate their performance.

For this, one of the most recommended methods involves the use of indicators that are capable of comparing selected facts observed in reality and are characterised by pre-established parameters and goals for sustainability, because such indicators ensure that the assessment process significantly considers economic, social, and environmental dimensions.

However, there is a limitation to the use of a large number of disaggregated indicators, as well as of a single synthetic incorporating index. Accordingly, one proposition has been the sustainability barometer (SB), which allows for a graphical representation of the combination of a range of indicators in two dimensions. This allows for evolving a big picture of the state of the environment and society, facilitating the analysis of the interrelationship between the two.

The present work aims at comparing the performance of Brazilian states with regard to sustainable development, using a modification of the sustainability barometer proposed by Cetrulo et al. [1] as a tool.

\section{Sustainability Barometer (SB)}

The SB is a tool developed by Canadian experts connected to the International Union for Conservation of Nature (IUCN) and the International Development Research Centre (IDRC) for sustainability assessment. Through a set of integrated indicators, this tool seeks to analyse the interaction patterns of people and the environment by means of information regarding the quality of life and the rate of progress of a society towards sustainability (Prescott-Allen [2]; Van Bellen [3]).

For Prescott-Allen [4], it is a tool targeted towards public administration, governmental and non-governmental agencies, decision makers, and agents involved with sustainable development issues, which can be applied on both a macro (at the level of the global system) as well as a local scale.

The main feature of the SB is the combination of different indicators with specific measures, used in an integrated manner, via performance scales (Kronemberger et al. [5] and Prescott-Allen [2,6]). A potential benefit of the SB is its ability to represent characteristics that reveal more about the general state of the system through the choice of indicators that adequately portray the state of the environment and society. For this, the general concept of sustainable development should be represented in relation to welfare and the progress of human and ecological conditions, through quantitative indicators (Prescott-Allen [6]; Bossel [7]). 
The performance of each of the indicators that compose the dimensions of human and ecological well-being provides a signal that, alone, does not allow an analysis of the situation as a whole, but when combined, demonstrate their results through aggregate indicators. The graphical representation of these aggregate values enables a view of the general picture of the state of the environment and society and facilitates the analysis of the inter-relationship between both dimensions through the intersection of these two points (PrescottAllen [2]; Lucena et al. [8]; Van Bellen [9]).

The scale used in the sustainability barometer is divided into five sectors, ranging from sustainable to unsustainable, and representing the progress (or lack thereof) of a particular city, state or nation (Prescott-Allen [4]; Van-Bellen [9]).

\subsection{State Sustainability Barometer (SSB)}

The State Sustainability Barometer (SSB), proposed by Cetrulo et al. [1], is intended as a tool of government communication, aligned to the concept of sustainable development evaluation.

The SSB is proposed as a tool which serves to compare the situation of a state with respect to an established pattern as well as to that of other states for the purpose of benchmarking, a strategy which has rarely been explored by environmental indicators; this fact has been highlighted by Cetrulo et al. [10].

Thus, the pattern of sustainable development is based on the best performances achieved by the Brazilian states, the indicators selected from Brazilian governmental bases of communication.

\section{Method}

\subsection{Selection of indicators for the State Sustainability Barometer}

Because this involves a comparison among Brazilian states, it was necessary to find indicators that had already been established in the main information sources for all Brazilian states. In this way, the SSB indicators were chosen using three government periodicals, which were chosen because they contain a vast variety of indicators enough to represent human and environmental well-being; however, in isolation, they do not allow insight into the general condition of each national federation.

The documents used were as follows: (a) Sustainable Development Indicators (Indicadores de Desenvolvimento Sustentável, IDS), a compendium of indicators for monitoring the sustainability of development in Brazil, published by the Brazilian Institute of Geography and Statistics (IBGE), which is guided by the recommendations of the Commission for Sustainable Development of the United Nations; (b) Synthesis of Social Indicators (Síntese de Indicadores Sociais, SIS), a publication by the IBGE that presents social indicators for Brazilian States in order to provide fast and diverse information annually for the systematic monitoring of the conditions of life of the Brazilian population; and (c) Basic 
Data and Indicators for Healthcare (Indicadores e Dados Básicos para a Saúde, IDB), the result of an integrated action by the Ministry of Health, the IBGE, the Institute of Applied Economic Research (IPEA) and the Ministry of Social Security.

Once the sources of governmental information were selected, the central criterion used to select the indicators was the concept of sustainable development. This is because, for the studies contained in this paper, this concept is based on the expansion of human freedoms proposed by Sen [11], and necessitating the adoption of a broad set of indicators representative of various forms of freedom, which are part of this complex social framework. Thus, the SSB's dimension of 'human well-being' is composed of the sub-dimensions of demographics, education, economics, social justice, health, and safety.

Further, in relation to the concept of sustainable development used in this study, it was decided to use indicators that represent the ability to maintain the expansion of human freedoms in succeeding generations, respecting the supportive capacity of the ecosystems. To this end, the SSB's dimension of 'ecological well-being' consists of the sub-dimensions of sanitation, environmental health, vegetation coverage, soil pollution, and institutions.

After this selection was made, it was also possible to ensure the robustness of the SSB, since a total of 28 indicators were used (Cetrulo et al. [1]), which are explained in Figure 1.

\subsection{Preparation of the State Performance Scale}

The first step in constructing the State Performance Scale was the determination of the reference values, that is, the lower and upper limits of the established standard. The determination of these reference values was undertaken in order to represent the reality in Brazil, avoiding the use of standards determined internationally in very different contexts. To ensure that these references were accessible, the study used values found within the country, both for the lower as well as the upper boundaries; the lower limit for any one indicator was the worst performance found among all Brazilian states, and the upper limit was the best respective performance.

The State Performance Scale was constructed from the reference limits, which were obtained by staggering 5 groups between the values of the lower and upper limit, so that it could be correlated with the 5 groups of the General Barometer Scale.

\subsection{Transposing the performance value in the state scale to the Barometer scale}

As it is not possible to aggregate indicators on such different scales, the technique proposed by the barometer is to transpose the values into a scale of 0 to 100 , divided into 5 groups. 


\begin{tabular}{|c|}
\hline Human well-being \\
\hline Demographic indicators \\
\hline Life expectancy at birth (years) \\
\hline Overall mortality (number of deaths/thousand inhabitants/year) \\
\hline Degree of urbanisation $(\%)$ \\
\hline Population growth rate $2000-2010(\%)$ \\
\hline $\begin{array}{l}\text { Educational indicators } \\
\end{array}$ \\
\hline Literacy rate for people over 15 years of age $(\%)$ \\
\hline Percentage of people over 25 years of age with 15 or more years of schooling (\%) \\
\hline Economic indicators \\
\hline Monthly household income per capita (\% below $1 / 4$ of the minimum wage) \\
\hline GDP per capita $(\mathrm{R} \$)$ \\
\hline Gini index of the distribution of monthly income \\
\hline Household income per capita (below $60 \%$ of median) \\
\hline Social justice indicators \\
\hline Families with sufficient food $(\%)$ \\
\hline Relationship among income of people with black or brown/white skin \\
\hline Relationship among income of women/men \\
\hline Health indicators \\
\hline Number of doctors (per 1,000 inhabitants) \\
\hline Infant mortality rate below 1 year (per 1,000 live births) \\
\hline Number of inpatient beds (per 1,000 inhabitants) \\
\hline Number of health facilities (per 1,000 inhabitants) \\
\hline Safety indicators \\
\hline Number of deaths by homicide (per 100,000 inhabitants) \\
\hline Mortality rate from traffic accidents (per 100,000 inhabitants) \\
\hline $\begin{array}{l}\text { Ecological well-being } \\
\end{array}$ \\
\hline Sanitation indicators \\
\hline$\%$ of houses without water supply \\
\hline$\%$ of households with sewage systems and/or septic tank \\
\hline$\%$ of proper disposal of waste \\
\hline $\begin{array}{l}\text { Environmental health indicators } \\
\end{array}$ \\
\hline $\begin{array}{l}\text { Number of hospitalisations related to inadequate environmental sanitation (per } 100,000 \\
\text { inhabitants) }\end{array}$ \\
\hline Vegetation coverage indicators \\
\hline Protected areas (\% of area) \\
\hline Soil pollution indicators \\
\hline Rate of fertiliser $(\mathrm{kg} / \mathrm{ha})$ \\
\hline Rate of pesticides $(\mathrm{kg} / \mathrm{ha})$ \\
\hline Institutional indicators \\
\hline Municipalities that have an active environmental city council \\
\hline Municipalities that actively participate in the river basin committee \\
\hline
\end{tabular}

Figure 1: Indicators selected for the SSB. 
To transpose the State Performance Scale to the General Barometer Scale, it was necessary to perform a simple linear interpolation of the values obtained by the state to the SB scale through the following eqn (1):

$$
V B=\frac{P S B i+(R V-P S S B i) x(P S B f-P S B i)}{(P S S B f-P S S B i)}
$$

where: VB - Value on the Barometer Scale; PSBi - Initial value on the Performance Scale Barometer; PSBf - Final value on the Performance Scale Barometer; RV- Real Value of the State; PSSBi - Initial value on the Performance Scale of the State Barometer; PSSBf - Final value on the Performance Scale of the State Barometer.

\subsection{Developing the index for each dimension and graphical}

After finding the value of each indicator within the Barometer Scale, it was necessary to compose an arithmetic mean for each dimension, 'human wellbeing' and 'ecological wellbeing', according to eqns (2) and (3). It was also possible to generate an index for the sub-dimensions (eqn (4)).

$$
\begin{aligned}
E W B & =\sum_{i=1}^{N} V B E_{i} / N \\
H W B & =\sum_{i=1}^{N} V B H_{i} / N \\
I S D & =\sum_{i=1}^{N} V B S_{i} / N
\end{aligned}
$$

where: EWB - Ecological Well-Being index; HWB - Human Well-Being index; ISD - Index for each sub-dimension; VBE - Value on the Barometer scale (ecological); VBH - Value on the Barometer scale (human); $\mathrm{N}$ - Total Number of indicators; i - Indicator.

The indices calculated for the two dimensions were then plotted on a twodimensional graph, where each axis is divided into the groups of the SSB scale. The meeting point between the ecological wellbeing index and the human wellbeing index represents the position of a state in Brazil, in relation to the established standard, which is presented in the SSB graph.

\section{Results and discussion}

The results of the performance in relation to sustainable development, for each Brazilian state, are plotted in the following figure. It is observed that only three 


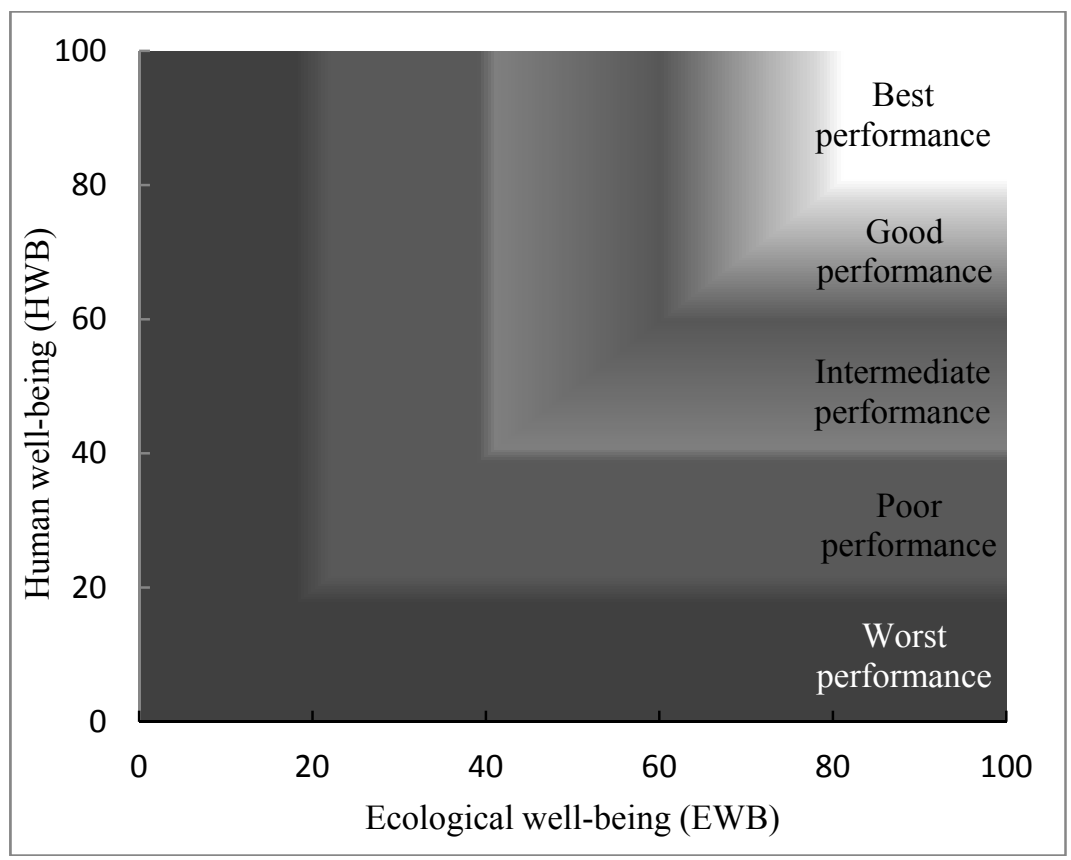

Figure 2: Graphical representation of State Sustainability Barometer.

states are located in the 'underperforming' sector, one from the north of the country and two from the northeast. The three southern states demonstrated high performance, depending on the methodology used. All the remaining 20 states lie in the middle range of performance.

Results demonstrate that the Brazilian state with the best performance in sustainable development is Rio Grande do Sul (71.50 HWB; 67.43 EWB), followed by Santa Catarina (71.83 HWB; 66.42 EWB), and Paraná (66.26 HWB; 61.44 EWB). The state with the worst performance is Alagoas (30.34 HWB; 36.52 EWB), followed by Maranhão (35.93 HWB; 47.79 EWB), and Rondônia (50.46 HWB; 36.1 EWB).

Although most states present an intermediate degree of performance, it is noted that, among them, the states of the northern, northeastern, and midwestern regions are much closer to the underperformance group, while the southeastern states are much closer to the good-performance group.

Figure 3 shows the performance of each Brazilian region. It is observed that the south had the best performance (the good-performance group), followed by the southeast, the performance of which was characterised as intermediary but with a high index of human wellbeing. The northern region presented an intermediate performance, while the indices of human and ecological wellbeing displayed a good balance. The performance of the northeastern region is very close to the low-performance group, due to the low index of human wellbeing, while the midwestern region showed a similar performance on account of the low index of ecological wellbeing. 

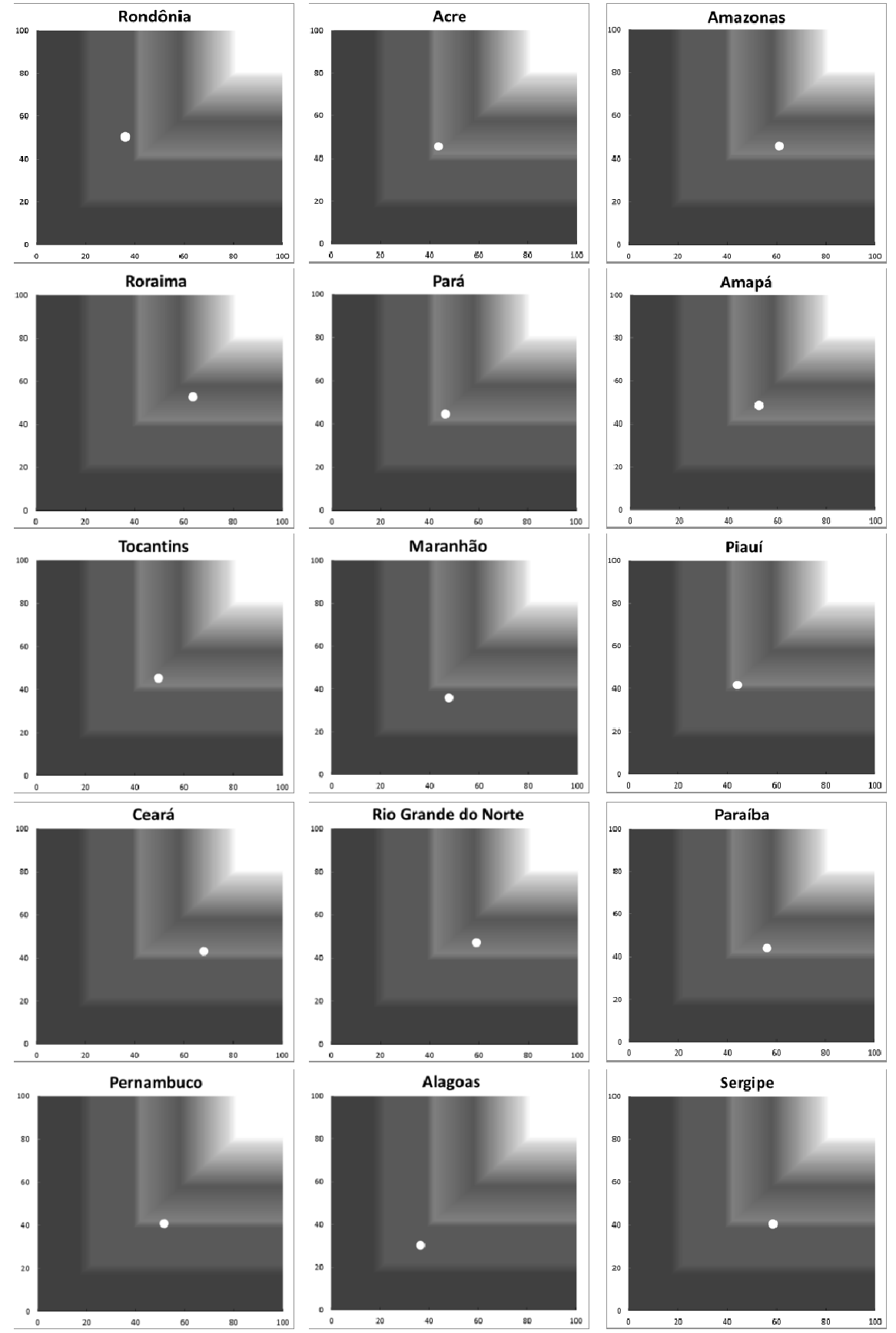

Figure 3: State Sustainability Barometer for Brazilian states. 

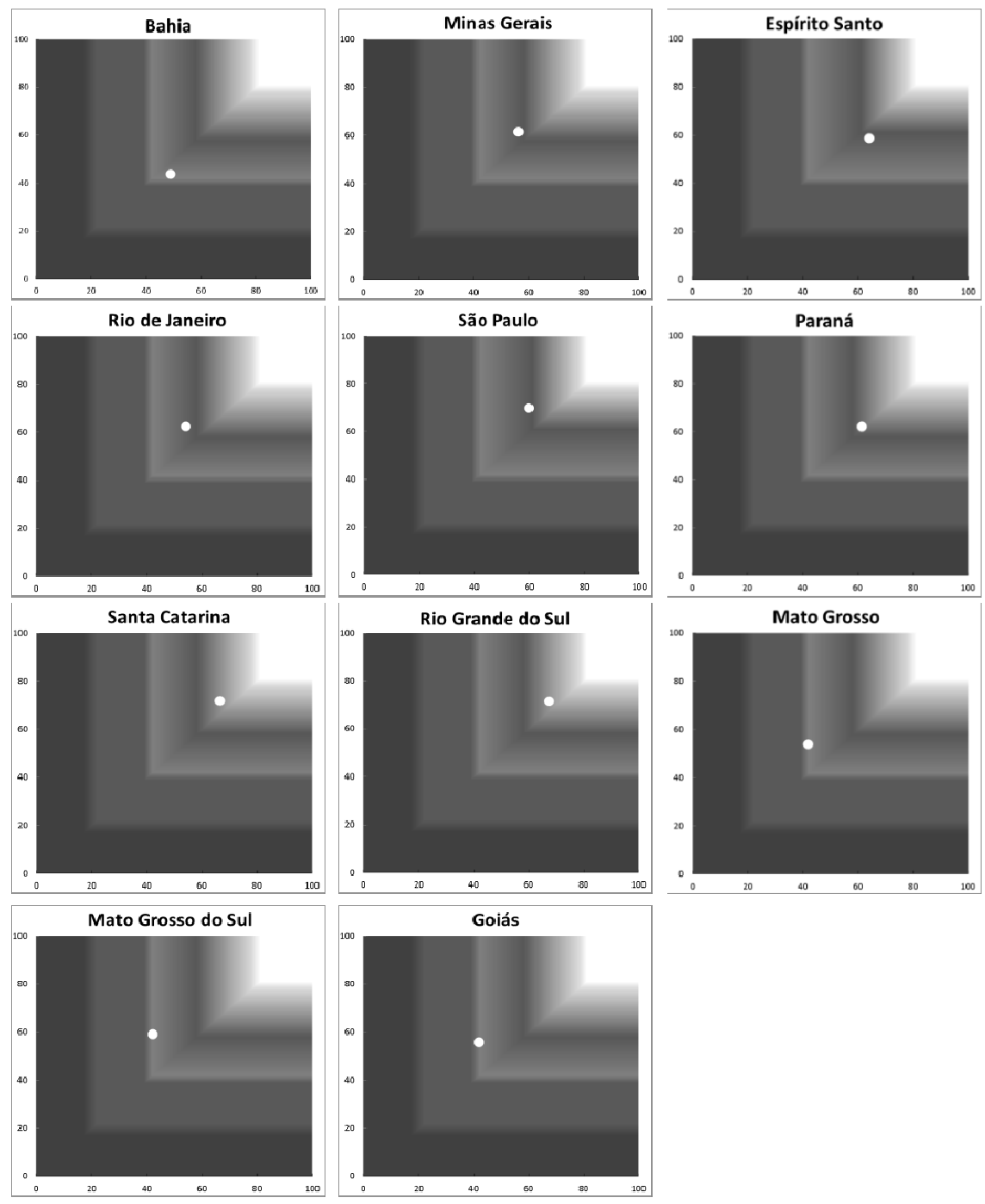

Figure 3: $\quad$ Continued.

Considering that the SSB's focus is on evaluating the sustainable development of human societies, ensuring the expansion of the freedoms of each individual according to Sen [11], and ensuring that this expansion was represented by indicators of social demographics, education, economics, social justice, health and safety, it is observed that the vast majority of Brazilian states cannot be considered as developed, since they do not provide tools and opportunities to meet the needs of individuals.

As discussed in the work of Moldan et al. [12], social indicators are presented as critical factors for the maintenance of a society. In that sense, the states of the 


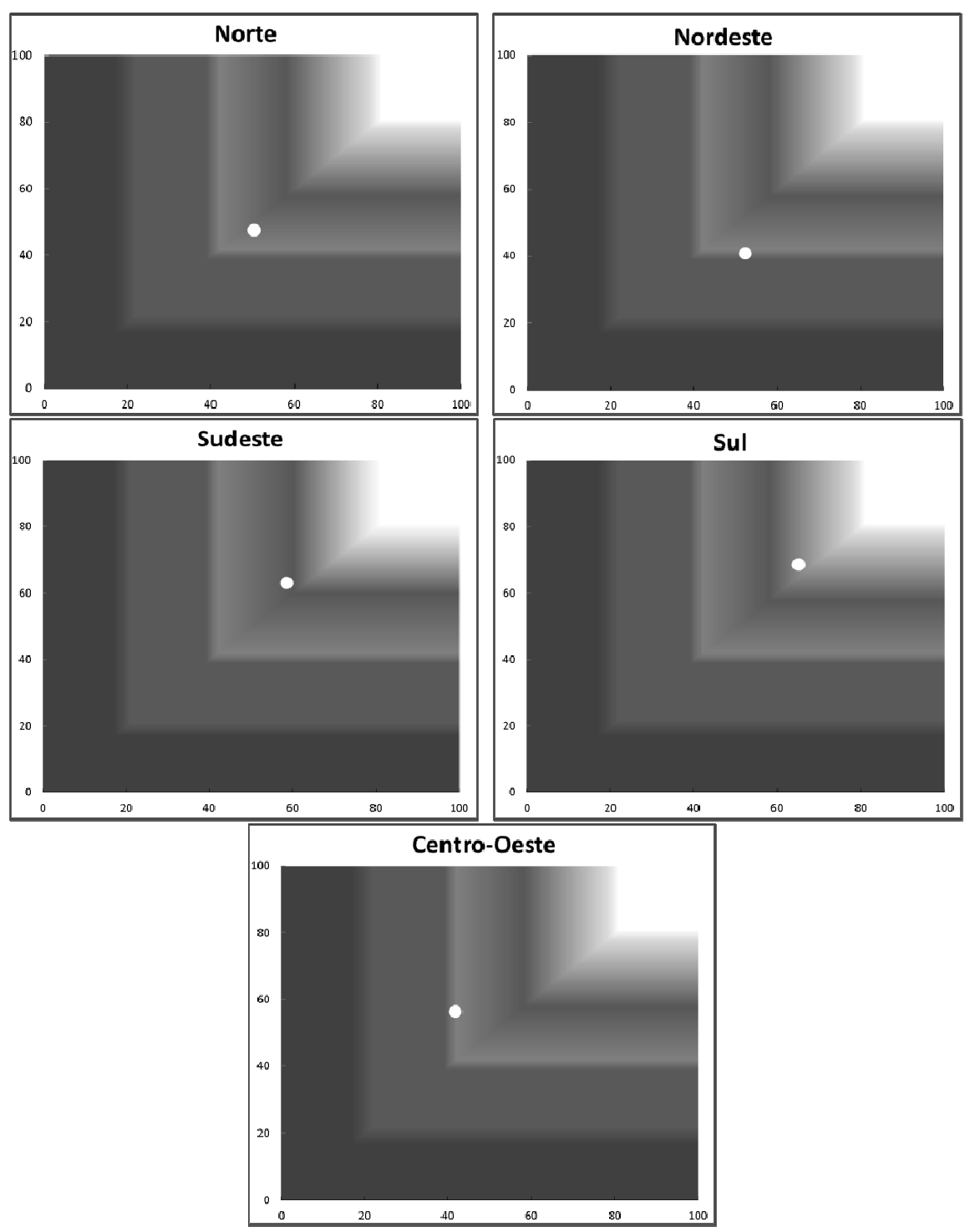

Figure 4: Sustainability Barometer for Brazilian regions.

north and northeast regions, primarily, do not display an adequate level of development of the respective society.

Regarding the factors of ecological well-being, most Brazilian states do not display an adequate performance. For the SSB, these factors represent the sustenance of society through time, considering the quality of the middle as being of primary importance. Therefore, only the development of the southern 
states can be considered as suitable for the temporal continuity of society, considering the quality of the relationship between humanity and nature.

It is important to highlight that the easy graphical display of the sustainability barometer enables benchmarking between states, concerning both the end result as well as individual dimensions. Furthermore, it is possible to calculate the index for each sub-dimension (ISD), which can serve as the basis of information for the management of the state itself. Therefore, this information can facilitate the targeting of resources and efforts to improve the sub-dimensions demonstrating the worst performance.

In this sense, these possibilities corroborate the work of Prescott-Allen [4], which presents the barometer as a management and decision-making tool regarding sustainable development, enabling intervention by the public authorities and, in addition, easing the difficulties of visualising the critical areas of likely intervention presented by the synthetic indices, as discussed in the work of Veiga [13].

\section{Conclusion}

The comparison between the performance of Brazilian states with regard to sustainable development points to a significant regional disparity. It was observed that the further north one travels, the worse the performance, and the further south, the better the performance.

Rio Grande do Sul, Santa Catarina, and Paraná were the only states in the good performance group, while Alagoas, Maranhão, and Rondônia were the only ones in the low-performance group. Other states present an intermediate degree of performance, with the southeastern states being closer to the goodperformance group and the northern, northeastern, and midwestern regions being closest to the low-performance group.

The inter-region comparison conducted shows that only the southern region is in a good-performance group, while all the other regions lie in the intermediary group, although the performance of the southeastern region is closer to the goodperformance group.

\section{References}

[1] Cetrulo; T.B., Molina, N.S. \& Malheiros, T.F., Indicadores de sustentablidade: proposta de um barômetro de sustentabilidade estadual, Revista Brasileira de Ciências Ambientais, 29(1), 2013.

[2] Prescott-Allen, R., Assessing progress toward sustainability: the system assessment method illustrated by wellbeing of nations, IUCN: Cambridge, 1999.

[3] Van-Bellen, M.H., Indicadores de Sustentabilidade: uma análise comparativa, FGV: Rio de Janeiro, 2006.

[4] Prescott-Allen, R., Barometer of Sustainability: measuring and communicating wellbeing and sustainable development, IUCN: Cambridge, 1997. 
[5] Kronemberger, D.M.P., Clevelario Jr., J., Nascimento, J.A.S., Collares, J.E.R., Silva, L.C.D., Desenvolvimento Sustentável no Brasil: uma análise a partir da aplicação do Barômetro da Sustentabilidade. Sociedade \& Natureza, 20(1), pp. 25-50, 2008.

[6] Prescott-Allen, R., The Wellbeing of Nations: a country-by-country index of quality of life and the environment. Washington, DC: Island Press, 2001.

[7] Bossel, H., Indicators for sustainable development: Theory, Method, application. IISD: Winnipeg, 1999.

[8] Lucena, A.D., Cavalcante, J.N. \& Cândido, G.A., Sustentabilidade do município de João Pessoa: uma aplicação do barômetro da sustentabilidade. Revista Brasileira de Gestão e Desenvolvimento Regional, 7(1), pp. 19-49, 2001.

[9] Van-Bellen, M.H., Desenvolvimento Sustentável: Uma descrição das principais ferramentas de avaliação. Ambiente \& Sociedade, 7(1), pp. 2-22, 2004.

[10] Cetrulo, T.B.; Molina, N.S. \& Malheiros, T.F., Indicadores de postura ambiental do setor de produção de etanol de cana de açúcar (Chapter 19). Indicadores de sustentabilidade e gestão ambiental, ed. A. Phillippi Jr. \& T. F. Malheiros, Manole: Barueri, 2012.

[11] Sen, A.K., Desenvolvimento como Liberdade. Companhia das letras: São Paulo, 1999.

[12] Moldan, B.; Janouskova, S. \& Hak, T., How to understand and measure environmental sustainability: Indicators and targets. Ecological Indicators, 17(1), pp. 4-13, 2012.

[13] Veiga, J.E., Indicadores socioambientais: evolução e perspectivas. Revista de Economia Política, 29(4), pp. 421-435, 2009. 